\title{
The Weight of Numbers
}

\section{Describe what you made.} The Weight of Numbers is an interactive installation. It transforms and sends messages via its mechanical parts. Using a computer keyboard and a small LCD panel, participants first type a short message. After pressing Enter, the message is sent via steel balls to a monitor located three feet away. Each set of steel balls carries an encoded five-digit signal. The balls roll on steel tubes from one side to another to send the message. In the messagetransmission process, the digital signals are embodied in physical entities.

\section{Briefly describe the process of how this was made.}

The concept for the Weight of Numbers comes from a course project I did at Shih Chien University called "Evocative Object." For this project, students had to choose a particular evocative object and engage in a dialogue with it by designing an interactive artifact. The object I chose was a vintage mechanical calculator. It is part of my father's collection. I played with it very often in my childhood.

This calculator is made from metal and it weighs a lot. I was impressed by its accuracy and reliability. In contrast with the modern lightweight digital calculator, this mechanical calculator provoked my

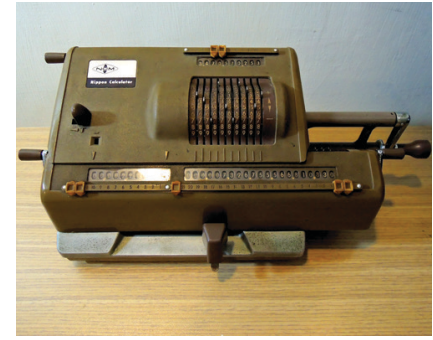

$\rightarrow$ This old mechanical calculator provided the concept for the project.

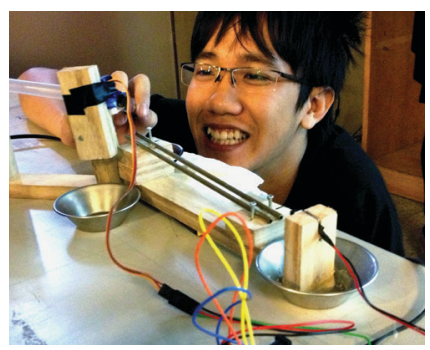

$\rightarrow \mathrm{Hsin}-\mathrm{Hao}$ Chen with the very first testing prototype.

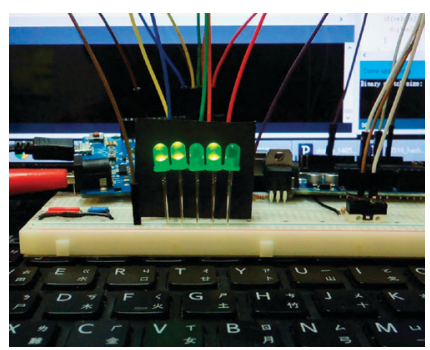

$\rightarrow$ Testing the encoding process of five-bit binary code.

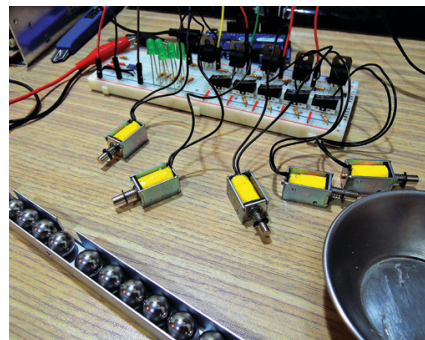

$\rightarrow$ Testing the circuit of the steel ball dispense rack.

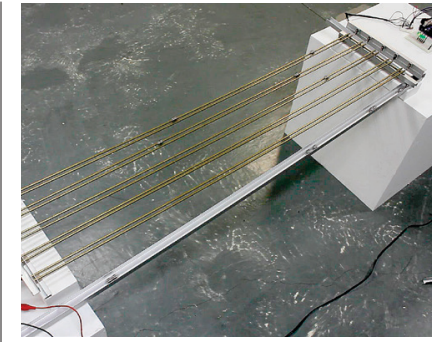

$\rightarrow$ Barebones system assembly.

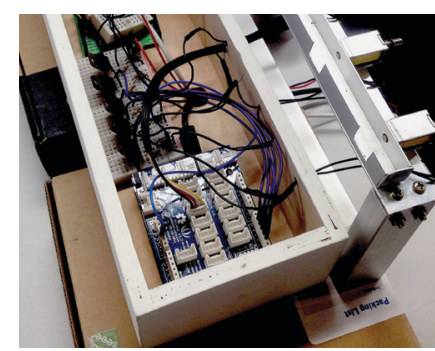

$\rightarrow$ Internal wiring

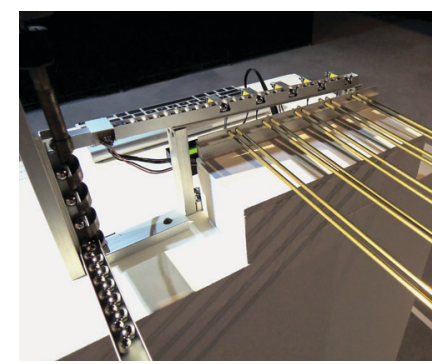

$\rightarrow$ The recycling system for the steel balls was designed for exhibitions.

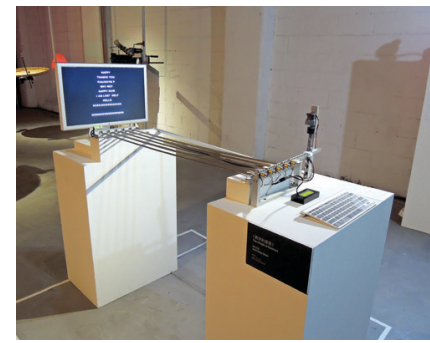

$\rightarrow$ The Weight of Numbers being exhibited at the Digital Art Festival Taipei. All components were attached to the display cabinet. interest in interpreting the relationship between the digital and the physical world. In the Weight of Numbers, I attempt to add physical weight to a digital signal.

What for you is the most important/interesting thing about what you made? I intentionally complicate the process of digital messaging through using mechanical parts. I have seen many interesting machines and enjoy studying how they work. Therefore, I tend to build function-oriented installations. By designing interesting mechanical movement, I want to raise viewers' curiosity and bring back the inspiring sense of texture that has gradually died away in this digital era.

\section{What materials and tools} did you use?

To emphasize the sense of weight and speed, I used metal tubes for the ball-rolling tracks. Just like my father's vintage calculator, the Weight of Numbers also needs very precise mechanical control to maintain stability and durability. I also used metal to build the dispense rack. I was very satisfied with the final result, especially its appearance and the sound of the collisions. Compared with the plastic materials used in mass production nowadays, the appearance and texture of metal 


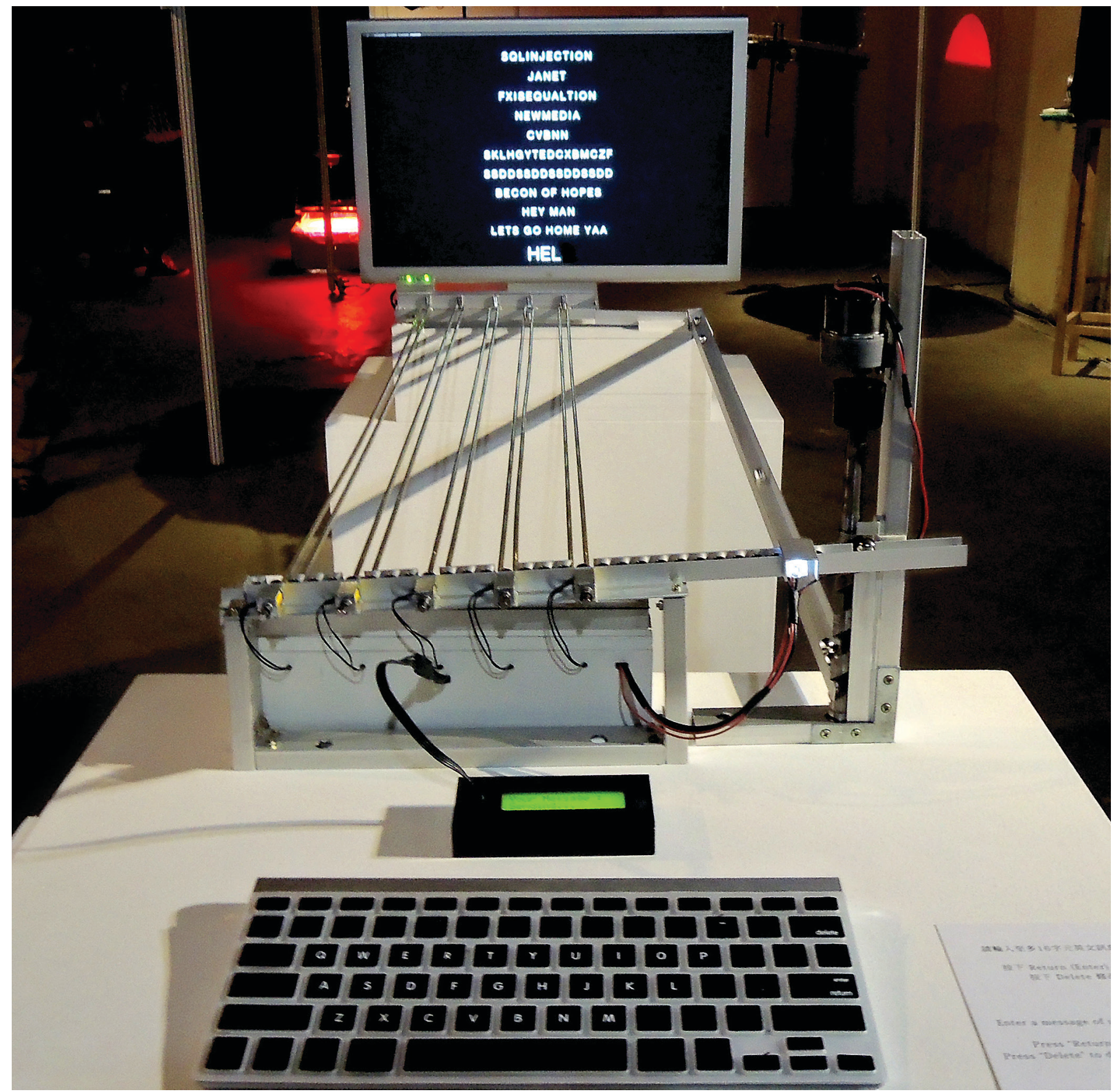

$\rightarrow$ The installation still functions precisely after cycling thousands of times.

present my thoughts more precisely.

\section{What was the biggest} surprise in making this? The early version of this installation didn't have the steel-ball recycling system. To meet the requirements for attending exhibitions, I started to look for solutions and found a spiral drill bit. It seemed like a wild idea at the beginning, but with some adjustments in the position and rotating speed, the recycling system works well.

\section{What will you repeat in} another project that you did well in this project?

I always seek to connect digital elements and the real world by building installations running multiple types of media and offering real-time interaction and feedback. I hope they provide possibilities for the development of future technology products.

(1) Hsin-Hao Chen, Creative Media Group, Shih Chien University $\rightarrow$ csh7183dgmail.com

(ㄹ) http://cargocollective.com/ $\mathrm{CSH} /$ The-Weight-of-Numbers
I want to bring back the inspiring sense of texture that has gradually died away in this digital era. 